\title{
Crystal structure and Mössbauer study of $\mathrm{FeAl}_{2} \mathrm{O}_{4}$
}

\author{
Ilona Jastrzębska, \\ Jacek Szczerba, \\ Pawel Stoch, \\ Artur Blachowski, \\ Krzysztof Ruebenbauer, \\ Ryszard Prorok, \\ Edyta Śnieżek
}

\begin{abstract}
In this work the synthesis of hercynite from $\mathrm{Fe}_{2} \mathrm{O}_{3}$ and $\mathrm{Al}_{2} \mathrm{O}_{3}$ powders was carried out by arc-melting method under the protective argon atmosphere. The obtained material was characterized with the use of powder X-ray diffractometry (XRD) and Mössbauer spectroscopy (MS). A Mössbauer effect in hercynite obtained by the arc-melting method indicated the cations distribution in the spinel structure among the tetrahedral and octahedral interstices. The presence of $\mathrm{Fe}^{2+}$ ions was detected in both tetrahedral and octahedral sites while $\mathrm{Fe}^{3+}$ ions occupied only the octahedral interstices. The approximate formula of the obtained iron-aluminate spinel was as follows $\left(\mathrm{Fe}_{0.77}^{2+} \mathrm{Al}_{0.23}^{3+}\right)\left(\mathrm{Fe}_{0.07}^{3+} \mathrm{Fe}_{0.05}^{2+} \mathrm{Al}_{0.88}\right)_{2} \mathrm{O}_{4}$.
\end{abstract}

Key words: $\mathrm{FeAl}_{2} \mathrm{O}_{4} \cdot$ hercynite $・$ Mössbauer spectroscopy $\bullet$ spinel

I. Jastrzębska ${ }^{\bowtie}$, J. Szczerba, P. Stoch, R. Prorok, E. Śnieżek

Department of Ceramics and Refractories, Faculty of Materials Science and Ceramics, AGH - University of Science and Technology, 30 Mickiewicza Ave., 30-059 Kraków, Poland, E-mail: ijastrz@agh.edu.pl

\author{
A. Błachowski, K. Ruebenbauer \\ Mössbauer Spectroscopy Division, \\ Institute of Physics, \\ Pedagogical University, \\ 2 Podchorążych Str., 30-084 Kraków, Poland
}

Received: 18 June 2014

Accepted: 2 November 2014

\section{Introduction}

Hercynite $\left(\mathrm{FeAl}_{2} \mathrm{O}_{4}\right)$ is one of the endmembers of the spinel group minerals that have the general formula $\mathrm{A}^{2+} \mathrm{B}_{2}^{3+} \mathrm{O}_{4}$. This formula describes the spinel compound with normal cation distribution which means that all the divalent cations occupy tetrahedral sites $\left(\mathrm{T}_{\mathrm{d}}\right)$, whereas all the trivalent cations are located in the octahedral environment $\left(\mathrm{O}_{\mathrm{h}}\right)$ [1]. However, the intersite exchange of the cations is possible, for example hercynite crystal lattice commonly contains $\mathrm{Fe}^{3+}$ cations in the $\mathrm{O}_{\mathrm{h}}$ sites as a result of the formation process [2-4]. Furthermore, $\mathrm{Al}^{3+}$ ion occurrence in $\mathrm{T}_{\mathrm{d}}$ sites is also feasible. This disordering process can be described by the formula $\left(\mathrm{A}_{1-x} \mathrm{~B}_{x}\right)$ IV $\left(\mathrm{A}_{x} \mathrm{~B}_{2-x}\right)^{\mathrm{VI}} \mathrm{O}_{4}$, where $x$ defines disorder degree and symbols IV and VI refer to $\mathrm{T}_{\mathrm{d}}$ and $\mathrm{O}_{\mathrm{h}}$ coordination, respectively. When the $x$ parameter takes a value of 0 spinel possesses a normal cation distribution while for $x=1$ the distribution is fully inversed. Each spinel may be fully characterized by determination of three structural parameters $a, u$, and $x$, i.e. the lattice parameter, the oxygen positional parameter, and the cation inversion parameter, respectively. Iron-aluminate spinel, which is the concern of this work possesses regular symmetry and crystalizes in the space group $F d 3 m$ with the $\mathrm{Fe}^{2+}$ cation in site $8 a$ $(1 / 81 / 81 / 8)$, the $\mathrm{Al}^{3+}$ cations in site $16 d(1 / 21 / 2$ $1 / 2)$, and the anions $\mathrm{O}^{2-}$ in site $32 e(\mathrm{u} \mathrm{u} \mathrm{u})$ [4]. The aim of this study was to characterize hercynite synthesized by the non-traditional arc-melting method by means of the crystal structure determination, together with the local chemical environment and charge of iron in this spinel. 


\section{Experimental}

The sample of hercynite was synthesized by the arc-melting method (arc furnace, SpekoArc 300) using a stoichiometric mixture of pure analytical grade $\mathrm{Fe}_{2} \mathrm{O}_{3}$ and $\mathrm{Al}_{2} \mathrm{O}_{3}$ powders as precursors. The mixture was homogenized and pressed into pellets before the melting process. The XRD pattern of melted and subsequently powdered product was obtained at room temperature, using PANanalytical X'Pert Pro MPD $\mathrm{X}$-ray diffractometer in Bragg-Brentano geometry, with $\mathrm{CuK}_{\alpha}$ radiation $(\lambda=1.54056 \AA)$, in the $10^{\circ} \leq$ $2 \theta<90^{\circ}$ range. The structural parameters $a, u$, and $x$ were determined using the FullProf software [5].

Mössbauer measurements were performed in a transmission mode with the use of RENON MsAa-3 spectrometer equipped with the LND Kr-filled proportional detector and He-Ne laser based interferometer used to calibrate a velocity scale. A commercial ${ }^{57} \mathrm{Co}(\mathrm{Rh})$ source kept at room temperature was applied for $14.41-\mathrm{keV}$ resonant transition in ${ }^{57} \mathrm{Fe}$. The quadrupole splitting distribution (QSD) from the Mössbauer spectrum of $\mathrm{FeAl}_{2} \mathrm{O}_{4}$ was obtained by the use of the Voigt-based quadrupole splitting method. This methodology of spectra fitting assumes a certain number of $m$ generalized interstices, when each of them possesses their own continuous quadrupole split distribution. Each generalized site-specific QSD consists of certain number of Gaussian components which are described by the two site specific parameters $\left(\delta_{0}, \delta_{1}\right)$. The center shift, designated as $\delta_{m}$, is a linear function of QS (quadrupole splitting) as it is shown by the equation $\delta_{m}=\delta_{0}+$ $\delta_{1} \cdot \mathrm{QS}$, where $\delta_{0}$ is the value of $\delta_{m}$ if the distribution parameter takes the value 0 , and $\delta_{1}$ means the coupling of $\delta_{m}$ to a distributed parameter [6].

All the given isomer shift data are relative to $\alpha-\mathrm{Fe}$ throughout this paper. The Mössbauer absorbers were prepared in the powder form.

\section{Results and discussion}

Figure 1 presents XRD pattern of the obtained sample. All the diffraction lines were assigned as be-

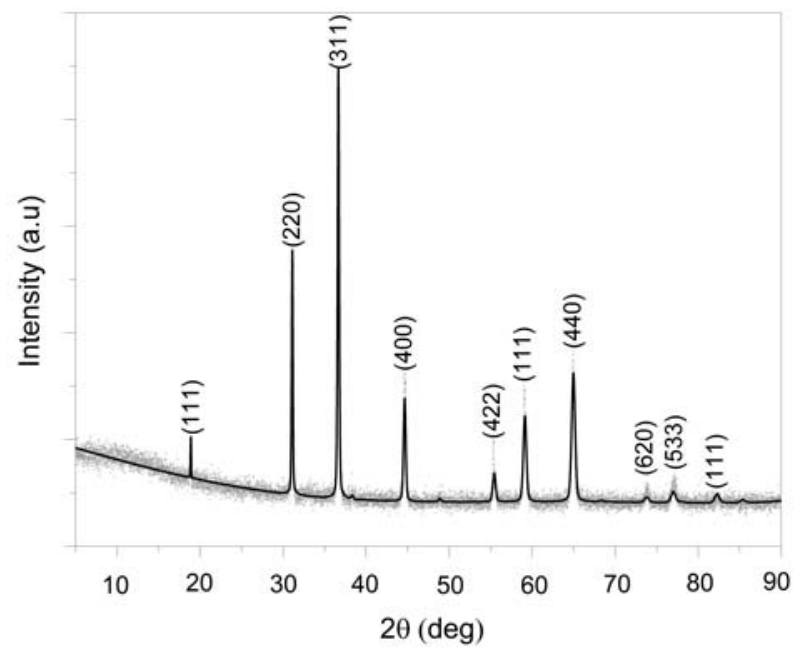

Fig. 1. XRD pattern of the arc-melted $\mathrm{FeAl}_{2} \mathrm{O}_{4}$. longing to hercynite (JCPDS 007-0068) with regular symmetry of the $F d 3 m$ space group. The X-ray diffraction pattern shows that other phases do not exist in the investigated sample. Thus, synthesis by the arc-melting method resulted in the pure hercynite formation. The lattice parameter $a$ of hercynite was determined as 8.1320(9) $\AA$, while for the sintered one it was found to take the value of 8.1646(3) $\AA$ [7]. If we consider theoretical Fe-Al spinel with the normal structure, the $a$ parameter should be estimated on $8.1409 \AA$ [4]. Hence, the value of the lattice parameter obtained in this study is closer to the theoretical one. The slight difference between the theoretical and measured value of the lattice parameter may be related to the thermal history of the sample as well as distribution of $\mathrm{Fe}^{2+}, \mathrm{Fe}^{3+}$, and $\mathrm{Al}^{3+}$ ions between the two possible types of cavities.

The Mössbauer spectrum of the melted sample is shown in Fig. 2 and it was fitted using two quadrupole split distributions which correspond to di- and trivalent iron sites. The obtained hyperfine interaction parameters are listed in Table 1 . The first component of the lower mean shift $0.364 \mathrm{~mm} / \mathrm{s}$ could be assigned to $\mathrm{Fe}^{3+}$ in octahedral coordination. The second component was fitted assuming two Gaussian distributions of quadrupole splitting (QS) parameters corresponding to $\mathrm{Fe}^{2+}$ in tetrahedral and octahedral sites. The lower mean QS value distribution of $1.414 \mathrm{~mm} / \mathrm{s}$ is due to iron in $T_{d}$ sites, while the higher of $2.158 \mathrm{~mm} / \mathrm{s}$ is generated by iron in the $\mathrm{O}_{\mathrm{h}}$ coordination. The proposed model and the obtained values of hyperfine interaction parameters are in a good agreement with those previously obtained by Yagnik et al. [8].

The quantitative composition of the sample was estimated through the relative areas of the components. The greatest area comprising approximately $77 \%$ of $\mathrm{Fe}_{\text {tot }}$ was found for tetrahedrally coordinated $\mathrm{Fe}^{2+}$ ions at $\mathrm{T}_{\mathrm{d}}$ sites. About $13.5 \%$ of $\mathrm{Fe}_{\text {tot }}$ could be assigned to divalent iron in the octahedral sites. The rest of the iron ions were $\mathrm{Fe}^{3+}$ occurring in the octahedral sites. The obtained results permitted to determine the cations distribution as well as the general formula of the synthesized spinel as $\left(\mathrm{Fe}_{0.77}^{2+} \mathrm{Al}_{0.23}^{3+}\right)^{\mathrm{IV}}\left(\mathrm{Fe}_{0.07}^{3+} \mathrm{Fe}_{0.05}^{2+} \mathrm{Al}_{0.88}\right)_{2}^{\mathrm{VI}} \mathrm{O}_{4}$.

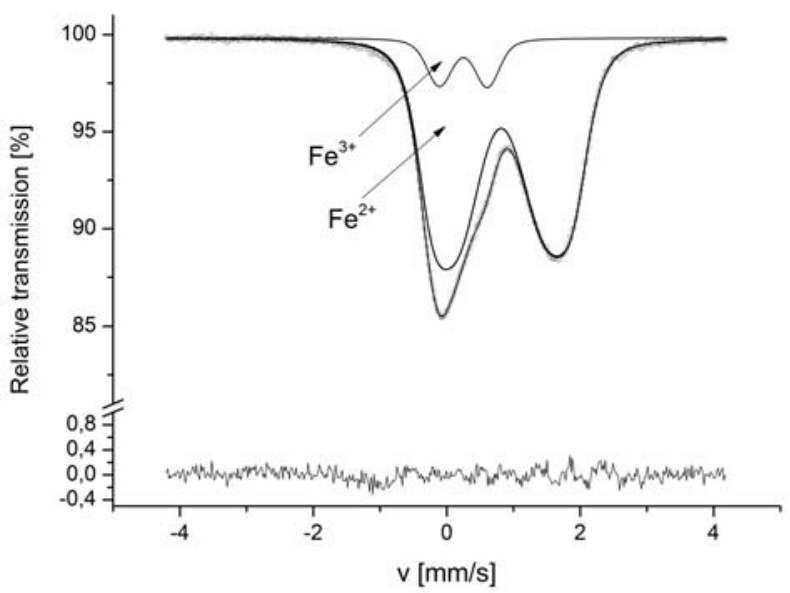

Fig. 2. Room temperature Mössbauer spectrum for the arc-melted $\mathrm{FeAl}_{2} \mathrm{O}_{4}$. 
Table 1. The Mössbauer hyperfine parameters for the arc-melted $\mathrm{FeAl}_{2} \mathrm{O}_{4}$

\begin{tabular}{llcccccccc}
\hline $\begin{array}{c}\text { Compo- } \\
\text { nent }\end{array}$ & $\begin{array}{c}\delta_{0} \\
{[\mathrm{~mm} / \mathrm{s}]}\end{array}$ & $\begin{array}{c}\delta_{1} \\
{[\mathrm{~mm} / \mathrm{s}]}\end{array}$ & $\begin{array}{c}\delta_{m} \\
{[\mathrm{~mm} / \mathrm{s}]}\end{array}$ & $\begin{array}{c}\mathrm{IS} \\
{[\mathrm{mm} / \mathrm{s}]}\end{array}$ & $\begin{array}{c}\text { QS } \\
{[\mathrm{mm} / \mathrm{s}]}\end{array}$ & $\delta \mathrm{QS}$ & $\begin{array}{c}\mathrm{A} \\
{[\%]}\end{array}$ & $\begin{array}{c}\text { Position } \\
\text { assignment }\end{array}$ & $\chi^{2}$ \\
\hline $\mathrm{Fe}^{3+}$ & $0.371(12)$ & $-0.009(10)$ & $0.365(19)$ & $0.364(12)$ & $0.721(10)$ & $0.276(8)$ & $9.5(5)$ & $\mathrm{Fe}^{3+}\left(\mathrm{O}_{\mathrm{h}}\right)$ & 1.67 \\
$\mathrm{Fe}^{2+}$ & $0.909(4)$ & $0.018(2)$ & $0.934(6)$ & $0.936(4)$ & $1.414(12)$ & $0.696(6)$ & $77.0(5)$ & $\mathrm{Fe}^{2+}\left(\mathrm{T}_{\mathrm{d}}\right)$ & 1.67 \\
$\mathrm{Fe}^{2+}$ & $0.909(4)$ & $0.018(2)$ & $0.948(6)$ & $0.936(4)$ & $2.158(10)$ & $0.306(15)$ & $13.5(5)$ & $\mathrm{Fe}^{2+}\left(\mathrm{O}_{\mathrm{h}}\right)$ & 1.67 \\
\hline
\end{tabular}

$\delta_{m}$ - central shift, $\delta_{0}-$ the value of $\delta_{m}$ if the distribution parameter has a value of zero, $\delta_{1}-$ the coupling of $\delta_{m}$ to a distributed parameter, IS - isomer shift, QS - quadrupole splitting (center of Gaussian QSD component), $\delta$ QS - width of the quadrupole split distribution, A - surface area.

The fraction of $\mathrm{Fe}^{3+}$ ions occupying $\mathrm{T}_{\mathrm{d}}$ cavities in the obtained spinel is low when compared to hercynite prepared by the others [9], what confirms effectiveness of the synthesis method applied in this study. The inversion parameter takes on the value of $x=0.23$, what is agreeable with the $x$ reported in Ref. [8]. The inversion parameter $x$ was used to refit the XRD pattern in order to determine the oxygen parameter $u$ which was estimated at $u=0.262$ what is close to the theoretical value of 0.25 .

\section{Conclusions}

The synthesis by the arc-melting method, with the use of $\mathrm{Al}_{2} \mathrm{O}_{3}$ and $\mathrm{Fe}_{2} \mathrm{O}_{3}$ powders as precursors, permitted to obtain the monophasic crystalline material, consisted only of iron-aluminate spinel (hercynite). The Mössbauer effect measurements showed partial cationic disorder in the melted hercynite and allowed the general formula of this spinel to be determined as follows $\left(\mathrm{Fe}^{2+}{ }_{0.77} \mathrm{Al}^{3+}{ }_{0.23}\right)\left(\mathrm{Fe}_{0.07}^{3+} \mathrm{Fe}^{2+}{ }_{0.05} \mathrm{Al}_{0.88}\right)_{2} \mathrm{O}_{4}$. The synthesized spinel compound was fully characterized by determination of all its structural parameters $a, u$, and $x$ taking the values of $8.1320 \AA, 0.262$, and 0.23 , respectively.

Acknowledgments. This work was partially supported by the Polish Ministry of Science and Higher Education, grant no. N N507 457637.

\section{References}

1. Hill, H. J., Craig, J. R., \& Gibbs, G. V. (1979). Systematics of the spinel structure type. Phys. Chem. Minerals, 4, 317-339.
2. Dormann, J. L., Seqqat, M., Fiorani, D., Nogues, M., Soubeyroux, J. L., Bhargava, S. C., \& Renaudin, P. (1990). Mössbauer studies of $\mathrm{FeAl}_{2} \mathrm{O}_{4}$ and $\mathrm{FeIn}_{2} \mathrm{~S}_{4}$ spin glass spinels. Hyperfine Interact., 54, 503-508. DOI: $10.1007 / \mathrm{s} 10751-004-7332-8$.

3. Russo, U., Carbonin, S., \& Giusta, A. D. (1996). Mössbauer spectral studies of natural substituted spinels. In G. J. Long \& F. Grandjean (Eds.), Mössbauer spectroscopy applied to magnetism and material science (Vol. 2, Chapter 9). New York: Plenum Press.

4. Sickafus, K. E., Wills, J. M., \& Grimes, N. W. (1999). Structure of spinel. J. Am. Ceram. Soc., 82(12), 3279-3292. DOI: 10.1111/j.1151-2916.1999. tb02241.x.

5. Roisnel, T., \& Rodriguez-Carvajal, J. (2000). WinPLOTR: a Windows tool for powder diffraction patterns analysis. In Materials Science Forum: Proceedings of the 7 th European Powder Diffraction Conference, 20-23 May 2000, Barcelona, Spain (EPDIC 7) (pp. 118-123).

6. Rancourt, D. G., \& Ping, J. Y. (1991). Voigt-based methods for arbitrary-shape static hyperfine parameter distributions in Mössbauer spectroscopy. $\mathrm{Nucl}$. Instrum. Methods Phys. Res. Sect. B-Beam Interact. Mater. Atoms, 58(1), 85-97.

7. Lenaz, D., \& Skokby, H. (2013). Structural changes in the $\mathrm{FeAl}_{2} \mathrm{O}_{4}-\mathrm{FeCr}_{2} \mathrm{O}_{4}$ solid solutions series and their consequences on natural Cr-bearing spinels, Phys. Chem. Miner., 40(7), 587-595. DOI: 10.1007/ s00269-013-0595-3.

8. Yagnik, C. M., \& Mathur, H. B. (1968). A Mössbauer and X-ray diffraction study on the cation distribution in $\mathrm{FeAl}_{2} \mathrm{O}_{4}, J$. Phys. C, 2(1), 469-472. DOI: 10.1088/0022-3719/1/2/320.

9. Andreozzi, G. B., Baldi, G., Bernardini, G. P., Benedetto, F., \& Romanelli, M. (2004). ${ }^{57} \mathrm{Fe}$ Mössbauer and electronic spectroscopy study on a new synthetic hercynite-based pigment, J. Eur. Ceram. Soc., 24, 821-824. DOI: 10.1016/S0955-2219(03)00329-7. 